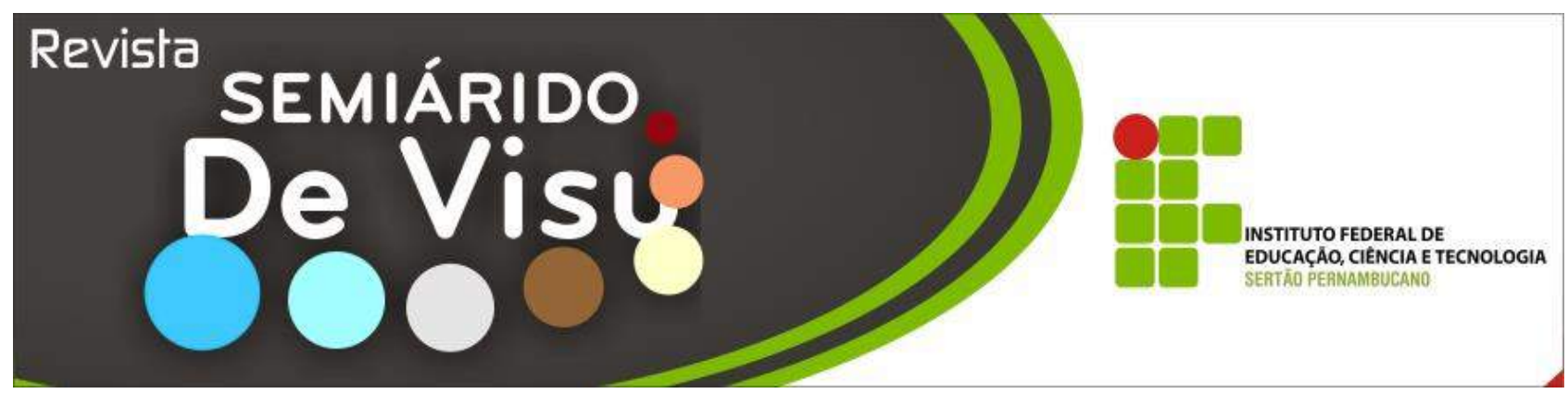

\title{
Estudos físico-químicos da alface cultivada sob diferentes condições de sombreamento
}

\author{
Daniel de Souza Santos ${ }^{1}$, Marcelo de Campos Pereira ${ }^{2}$, Eriverton da Silva Rodrigues ${ }^{3}$, Adriana de Carvalho Figueiredo \\ Rodrigues $^{4}$, Tetisuelma Leal Alves ${ }^{5}$, Edilaine Pereira de Sousa ${ }^{6}$
1,2,3,4,5,6 Instituto Federal do Sertão Pernambucano - campus Salgueiro. BR 232, Km 508, sentido Recife, Zona Rural - Salgueiro - Pernambuco - Brasil. CEP: 56000-000 / Telefone: (87) 3421-0050 / E-mail: daniel_santos1803199@hotmail.com ${ }^{\text {; }}$ marcelo.pereira@ifsertao-pe.edu.br² ; eriverton.rodrigues@ifsertao- pe.edu.br ${ }^{3}$; adriana.figueiredo@ifsertao-pe.edu.br ${ }^{4}$; tetisuelam.alves @ifsertao-pe.edu.br ${ }^{5}$; \\ edilaine.pereira@ifsertao-pe.edu.br ${ }^{6}$
}

\begin{abstract}
RESUMO: A alface é uma das hortaliças mais difundidas atualmente, sendo cultivada por todo país, porém é bastante sensível a condições adversas de temperatura, sendo tradicionalmente mais adaptada às temperaturas amenas, produzindo melhor nas épocas mais frias do ano. Mediante o exposto, a presente pesquisa teve por objetivo avaliar os efeitos da temperatura, incidência da radiação solar sobre o desenvolvimento da alface, através do sombreamento obtido a partir de telas de sombrite usado convencionalmente e um dispositivo confeccionado com cabos de vassoura e embalagens de leite longa vida e similares. Foram feitas análises físicas relacionadas a radiação solar e temperatura e químicas relacionadas ao $\mathrm{pH}$ do solo, teor de umidade e cinzas das folhas. Os resultados obtidos a partir do experimento demonstraram que a proteção oferecida pelo dispositivo proporcionou um maior conforto térmico à cultura, devido à redução da temperatura. A repetição desse experimento em períodos mais quentes do ano pode resultar em diferenças de temperaturas mais acentuadas, o que pode influenciar significativamente no desenvolvimento e composição química da cultura.
\end{abstract}

Palavras-chave: radiação solar, temperatura, hortaliça, sustentabilidade.

\section{Studies physical and chemical lettuce grown under conditions of different shade}

\begin{abstract}
Lettuce is one of the most widespread vegetables today, being cultivated all over the country, but it is very sensitive to adverse temperature conditions, being traditionally more adapted to mild temperatures, producing better in the coldest times of the year. The objective of this research was to evaluate the effects of temperature, the incidence of solar radiation on lettuce development, through the shading obtained from conventionally used sombrite screens and a device made with broomsticks and milk containers long life and the like. The results obtained from the experiment demonstrated that the protection offered by the device provided a greater thermal comfort to the crop due to the reduction of temperature. Repetition of this experiment in warmer periods of the year can result in more pronounced temperature differences, which can significantly influence the development and chemical composition of the crop.
\end{abstract}

keywords: solar radiation, temperature, vegetables, sustainability. 


\section{Introdução}

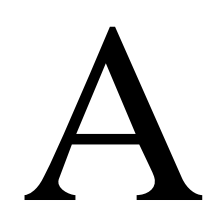

alface (Lactuca sativa L.) é uma das hortaliças mais difundidas atualmente, sendo cultivada por todo país, devido, principalmente, a grande divergência genética existente entre as cultivares utilizadas pelos produtores (SOUSA et al., 2007). Porém, é uma hortaliça bastante sensível a condições adversas de temperatura, sendo tradicionalmente mais adaptada às temperaturas amenas, produzindo melhor nas épocas mais frias do ano. (LOPES et al., 2002; OLIVEIRA et al., 2004).

$O$ município de Salgueiro - PE, localiza-se no Sertão Central de Pernambuco, região Semiárida do Nordeste brasileiro. Segundo Lima e Gatto (2014) essa região é problemática em termos de recursos naturais, além de estar sujeita à ocorrência de secas frequentes, que contribuem para evidenciar o frágil equilíbrio existente em sua base econômica e social.

Além das secas, a região apresenta elevadas temperaturas e luminosidade que, Segundo Makishima, 1992; Setúbal \& Silva, 1992 tem impedido que a cultura do alface expresse todo o seu potencial genético, afetando o desenvolvimento das folhas, tornando-as fibrosas, reduzindo o seu ciclo cultural, permitindo a não formação de cabeças e comprometendo a sua produção, devido à antecipação da fase reprodutiva, o que reforça a importância do cultivo protegido da alface, principalmente em regiões que apresentam temperatura e luminosidade elevadas.

A luz, fator relevante para o cultivo de hortaliças, como a alface, tem complexa influência na produção das plantas. $\mathrm{O}$ aumento da irradiação solar pode aumentar a produção de fotoassimilados e sua disponibilidade para o crescimento da planta. Porém, a radiação solar quando excessivamente elevada, pode aumentar a taxa transpiratória da planta resultando em fechamento estomático e diminuição da fotossíntese, diminuindo o crescimento $\mathrm{e}$ desenvolvimento da planta (OTONI et.al, 2012).

Outro fator ocasiona a baixa produção dessa hortaliça na região são os rudimentares métodos de produção, uso de cultivares não adaptadas e manejo inadequado.

Em contrapartida, o consumo de hortaliças tem aumentado não só pelo crescente aumento da população, mas também pela tendência de mudança no hábito alimentar do consumidor, tornando-se inevitável o aumento da produção, havendo necessidade de produzila em grande quantidade e qualidade, bem como manter o seu fornecimento o ano todo (OHSE, 1999).

Mediante o exposto, a presente pesquisa teve por objetivo avaliar os efeitos da temperatura, incidência da radiação solar sobre o desenvolvimento da alface, através do sombreamento obtido a partir de telas de sombrite usado convencionalmente e um dispositivo confeccionado com cabos de vassoura e embalagens de leite longa vida e similares.

\section{Material e métodos}

A pesquisa foi conduzida na área experimental do IF Sertão-PE, Campus Salgueiro numa área destinada ao cultivo de hortaliças, sendo cada unidade experimental composta por um canteiro de $1,0 \mathrm{~m}^{2}$, onde foram implantadas quatro mudas de alface, cultivadas de forma orgânica. Foram utilizados três tratamentos: (1) sombreamento com sombrite; (2) sombreamento com dispositivo (Figura 1) e (3) pleno sol (testemunha), sendo utilizadas cinco repetições para cada tratamento.

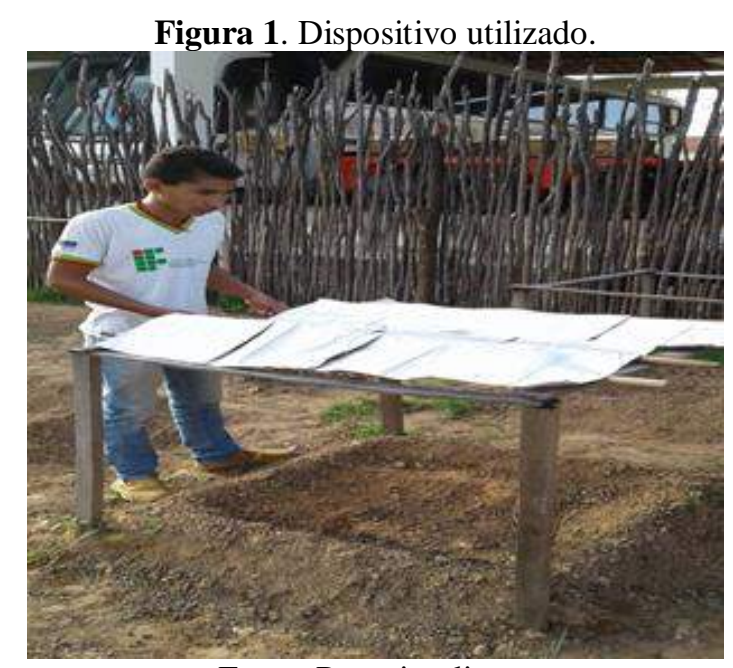

Fonte: Pesquisa direta. 
Os efeitos da incidência da radiação solar sobre a alface foram estudados através de sombreamento obtido a partir de tela de sombrite e de um dispositivo confeccionado com madeira para dá sustentação ao sombreamento e embalagens usadas como recipientes de leite longa vida e similares.

As analises foram realizadas nos meses de março, abril e maio de 2016. Na análise realizada em março ainda não tinham sido implantadas as mudas da alface. As medidas foram realizadas em um intervalo médio de 20 minutos, seguindo a sequência: cobertura com dispositivo, cobertura com sombrite e testemunha.

Foram utilizadas três formas de medições de temperatura: uso de termômetro infravermelho, multímetro digital no modo termômetro (Figura 2) e sensor de temperatura LM35 acoplado ao microcontrolador Arduino (Figura 3). Foram efetuadas medidas das temperaturas do solo no local, abaixo, acima da área sombreada e da temperatura das folhas da planta. Para cada medida, foi utilizado um equipamento diferente.

Figura 2: Multímetro digital no modo termômetro.

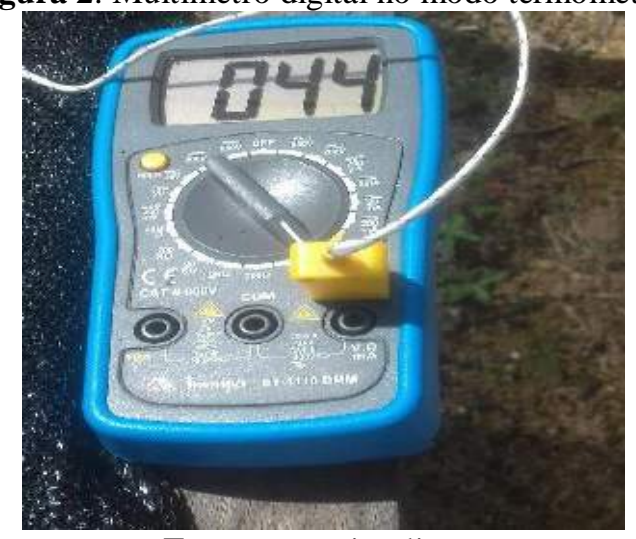

Fonte: Pesquisa direta.

Figura 3: Medidas utilizando o Arduino e o termômetro infravermelho.

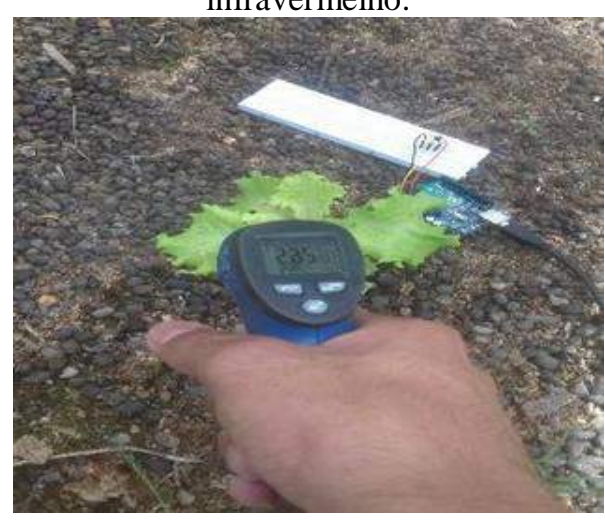

Fonte: Pesquisa direta.
Para obter melhores resultados, procurouse fazer as medidas em um dia ensolarado e com altas temperaturas para melhor evidenciar as diferenças de temperatura entre cada ponto do experimento. As medições no solo e nas folhas foram realizadas aproximando $o$ sensor infravermelho a uma distância de aproximadamente $10 \mathrm{~cm}$ do solo e da folha, respectivamente. $\mathrm{O}$ multímetro foi apoiado sobre a estrutura de madeira da estufa, em um ponto onde a luz solar incidia totalmente, sem nenhuma sombra. $\mathrm{O}$ sensor LM35 ficou em uma protoboard colocada próxima a planta, em uma área sombreada. Na protoboard, foram colocados os fios ligando o Arduino ao LM35. O computador foi colocado próximo a estufa e ligado via cabo USB ao Arduino para receber os dados do mesmo.

Além das análises físicas, foram feitas análises químicas relacionadas ao $\mathrm{pH}$ do solo, teor de umidade e cinzas das folhas. Os estudos destas mesmas foram realizados no laboratório de físico-química e da Unidade Acadêmica de Tecnologia em Alimentos (UATA) do Instituto Federal do Sertão Pernambucano campus Salgueiro, PE.

$\mathrm{O} \mathrm{pH}$ foi determinado pelo método potenciométrico, através de medidor digital da marca Tecnal modelo TEC-2, previamente calibrado com soluções tampão de pH 4,0 e 7,0. $\mathrm{O}$ teor de umidade foi determinado pelo método de secagem das amostras até peso constante, em estufa a $105{ }^{\circ} \mathrm{C}$ por $24 \mathrm{~h}$, sendo expressos em percentagem (\%), de acordo com as normas analíticas do Instituto Adolfo Lutz (2008). As cinzas foram determinadas após completa carbonização e incineração das amostras em mufla a $550{ }^{\circ} \mathrm{C}$, até a obtenção de um resíduo isento de carvão, com coloração branca acinzentado, de acordo com metodologia preconizada em AOAC (1997), sendo expressos em percentagem $(\%)$.

Foram feitas a análise de variância e a comparação de médias, pelo teste de Tukey, a $10 \%$ de nível de significância, para os dados de teor de umidade e cinzas.

\section{Resultados e discussão}

As plantas de alface cultivadas de forma orgânica apresentaram desenvolvimento 
satisfatório, com pH do solo igual a 7,5. Em relação a determinação de temperatura os gráficos 1, 2, 3, 4, 5, 6, 7, 8 e 9 apresentam os valores obtidos para este parâmetro nas unidades experimentais nos seguintes pontos de aferição: 1. abaixo dos sombreamentos; 2. do solo e 3. das folhas, fornecidas pelo dispositivo, sombrite e testemunha, respectivamente.

Gráfico 1. Dados de temperatura obtida abaixo do dispositivo.

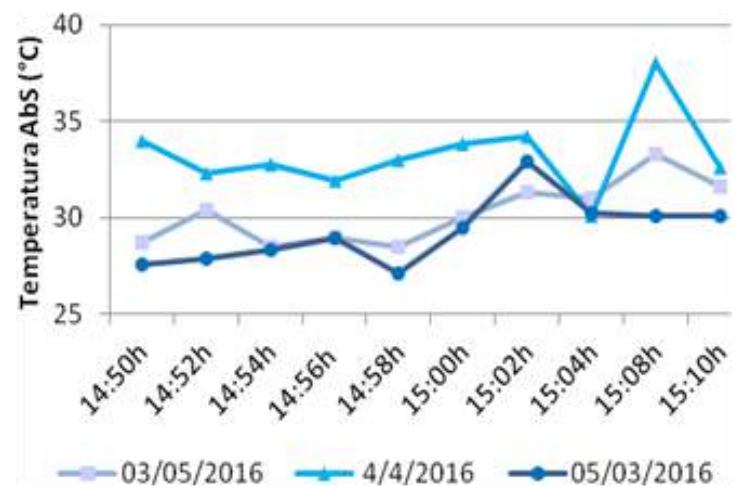

Fonte: Pesquisa direta.

Gráfico 2. Dados de temperatura obtida abaixo do sombrite.

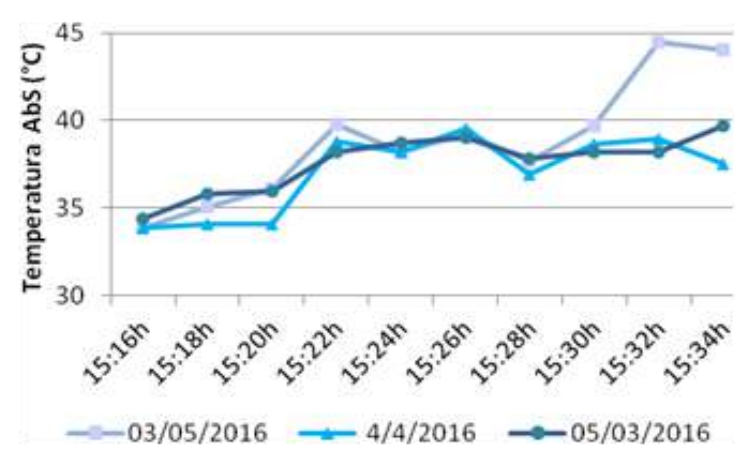

Fonte: Pesquisa direta.

Gráfico 3. Dados de temperatura ambiente obtida sem sombreamento.

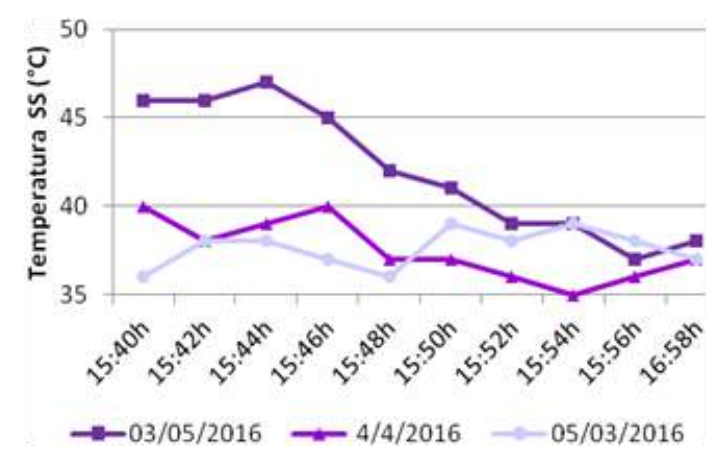

Fonte: Pesquisa direta.
Gráfico 4. Dados de temperatura do solo obtida abaixo do dispositivo.

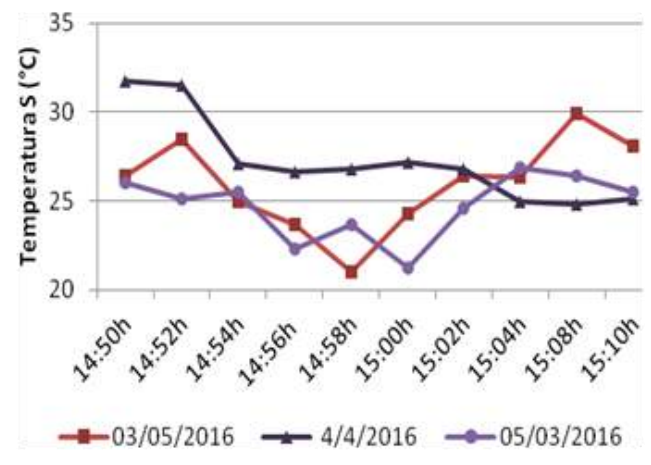

Fonte: Pesquisa direta.

Gráfico 5. Dados de temperatura do solo obtida abaixo do sombrite.

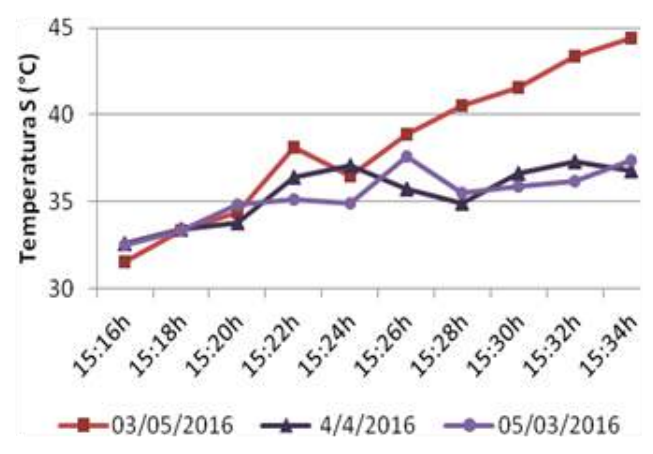

Fonte: Pesquisa direta.

Gráfico 6. Dados de temperatura do solo obtida na testemunha.

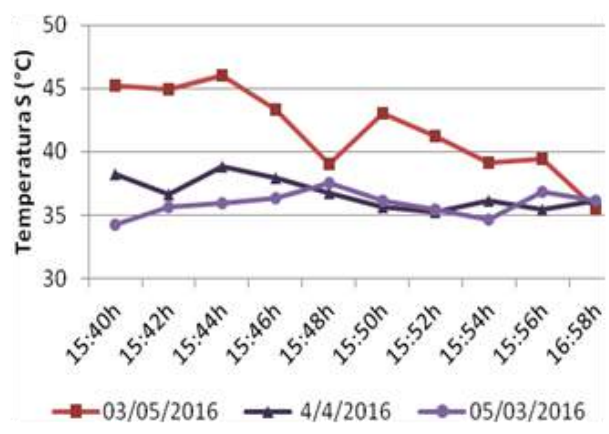

Fonte: Pesquisa direta.

Gráfico 7. Dados de temperatura obtidos na folha (dispositivo).

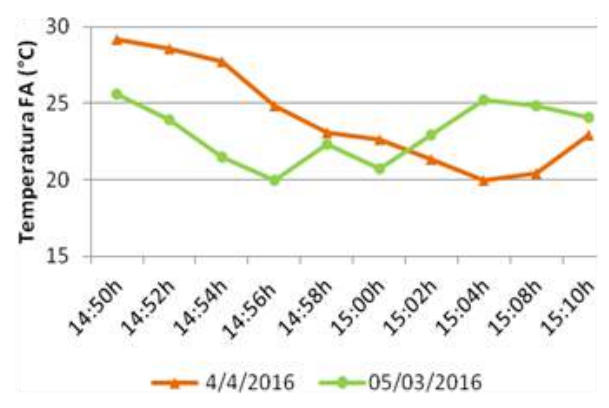

Fonte: Pesquisa direta. 
Gráfico 8. Dados de temperatura obtidos na folha (sombrite).

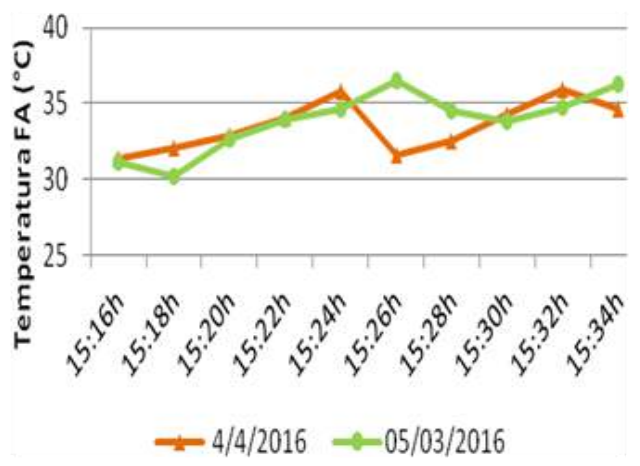

Fonte: Pesquisa direta.

Gráfico 9. Dados de temperatura obtidos na folha (testemunha).

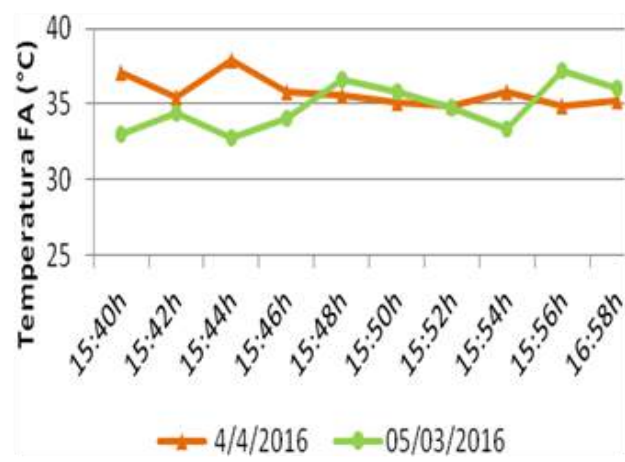

Fonte: Pesquisa direta.

De acordo com os dados obtidos pode-se evidenciar que a temperatura obtida a partir do dispositivo foi sempre inferior aos outros dois experimentos, comprovando sua eficiência no controle desse parâmetro. Resultados similares foram obtidos por Barros et al. (2015), que trabalhando com dispositivo similar, verificou que a temperatura aferida abaixo desse dispositivo era, em média $10{ }^{\circ} \mathrm{C}$ inferior à temperatura aferida na parte externa, proporcionando um maior conforto térmico à cultura.

O experimento com tela de sombrite (preta) diminuiu apenas a incidência direta da luz, porém, não influenciou na redução da temperatura, não havendo diferença significativa, quando comparado com a testemunha. Isso demonstra que o dispositivo se mostrou mais eficiente no controle da temperatura do que a tela de sombrite. Segundo Aburre et al. (2004) as telas de sombreamento e termo-refletoras além de reduzir a luminosidade do ambiente podem reduzir a temperatura em torno de 10 a $20 \%$ e Leite et al. (2003) verificou que a tela termorefletora apresentou maior produtividade que em campo aberto no verão e não reduziram a produtividade no inverno.

Segundo Makishima, 1992; Setúbal \& Silva, 1992 a adaptação da alface a temperatura e luminosidade elevadas tem impedido que a cultura expresse todo o seu potencial genético, afetando o desenvolvimento das folhas, tornandoas fibrosas, reduzindo o seu ciclo cultural, permitindo a não formação de cabeças e comprometendo a sua produção, devido à antecipação da fase reprodutiva, o que reforça a importância do cultivo protegido da alface, principalmente em regiões que apresentam temperatura e luminosidade elevadas.

Os quadros 1 e 2 demonstram as análises de cinzas e teor de umidade, respectivamente.

Quadro 1 - Análise de cinzas das folhas de alface, teste de Tukey a 10\% de probabilidade.

\begin{tabular}{cc}
\hline Tratamentos & Médias \\
\hline Dispositivo & $1.150000 \mathrm{a}$ \\
Sombrite & $1.093333 \mathrm{a}$ \\
Testemunha & $1.003333 \mathrm{~b}$ \\
\hline
\end{tabular}

Fonte: Pesquisa direta.

Quadro 2 - Análise do teor de umidade das folhas de alface, teste de Tukey a 10\% de probabilidade.

\begin{tabular}{cc}
\hline Tratamentos & Médias \\
\hline Dispositivo & $93.300000 \mathrm{a}$ \\
Sombrite & $93.366667 \mathrm{a}$ \\
Testemunha & $93.366667 \mathrm{a}$ \\
\hline
\end{tabular}

Fonte: Pesquisa direta. 
A tabela 1 demonstra as análises de cinzas das folhas da alface, onde pode se observar que houve diferença significativa entre os experimentos com sombreamento e a testemunha (pleno sol), mostrando assim a importância do cultivo em sistema protegido na região semiárida. Já a tabela 2 mostra que o teor umidade apresentado nas folhas não diferiu significativamente entre os experimentos. Isto pode ser explicado pelo fato da coleta das folhas para análise ter ocorrido no início da manhã, com temperatura mais amena.

\section{Conclusões}

Os resultados obtidos a partir do experimento demonstraram que a proteção oferecida pelo dispositivo proporcionou um maior conforto térmico à cultura, devido à redução da temperatura. Já a tela de sombrite diminuiu apenas a incidência direta da luz. Apesar da diferença de temperatura ocorrida entre os experimentos, não houve diferença significativa no teor de cinzas, entre dispositivo e tela de sombrite. Porém, a repetição desse experimento em períodos mais quentes do ano, pode resultar em diferenças de temperaturas mais acentuadas, o que pode influenciar significativamente no desenvolvimento e composição química da cultura.

\section{Referências}

ABAURRE, M. O.; PUIATTI, M.; CECON, P. R.; COELHO, M. B.; HUAMAN, C. A.; PEREIRA, F.H.F.; AQUINO, L. A. Produtividade de duas cultivares de alface sob malhas termorrefletoras e difusoras no cultivo de outono-inverno. Horticultura Brasileira, v. 22, p. 615, 2004.

BARROS, M. D. S; PEREIRA, M. C.; RODRIGUES, E. S., MEDEIROS, R. S.; SOUSA, E. P.; ALVES, T. L. Agrofísica: utilização de embalagens reutilizáveis para controlar a temperatura sobre o cultivo da alface. Revista Semiárido De Visu, v. 3, n. 3, p. 134-140, 2015.
LIMA, J. P. R.; GATTO, M. F. A economia doSemiárido de Pernambuco: ainda "sem produção"?. Economia e Desenvolvimento, Recife, v. 13, n. 1, 2014.

LOPES, MC.; FREIER, M; MATTE, JD.; GÄRTNER, M.; FRANZENER, G; CASIMIRO, ELN.; SEVIGNANI, A. 2002. Absorção de nutrientes por diferentes cultivares de alface em cultivo hidropônico no período de inverno. Horticultura Brasileira, 20. (Suplemento 2, CD ROM).

MAKISHIMA, N. Cultivo de hortaliças. Brasília:CNPH, 1992. 26 p.

OHSE, S. Rendimento, composição centesimal e teores de nitrato e vitamina $\mathbf{C}$ em alface sob hidropônica. 1999. 103 p. (Doutorado em Fitotecnia) - Escola Superior de Agricultura Luiz de Queiroz, universidade de São Paulo, Piracicaba, SP, 1999.

OLIVEIRA, ACB.; SEDIYAMA, MAN.; PEDROSA, MW.; GARCIA, NC.; GARCIA, SLR. 2004. Divergência genética e descarte de variáveis em alface cultivada sob sistema hidropônico. Acta ScientiarumAgronomy 26: 211-217.

OTONI, B.da S.; MOTA. W. F. da.; BELFORT, G. R.; SILVA, A.R.S.; VIEIRA, J. C.B.; ROCHA, L. de S. Produção de híbridos de tomateiro cultivados sob diferentes porcentagens desombreamento. Revista Ceres, Viçosa, v.59, n.6, p.816-825, 2012.

SETÚBAL, J.W.; SILVA. A.M.R. Avaliação do comportamento de alface de verão em condições de calor no município de TeresinaPI. Horticultura Brasileira, Brasília, DF, v.10, n.1, p.69, 1992.

SOUSA, C. S.; BONETTI, A. M.; GOULART FILHO, L. R.; MACHADO, J. R. A.; LONDE, L. N.; BAFFI, M. A.; RAMOS, R. G.; VIEIRA, C. U.; KERR, W. E. Divergência genética entre genótipos de alface por meio de marcadores AFLP. Bragantia, v.66, p.11-16, 2007. 